\title{
Bisphosphonate therapy for spinal osteoporosis in Hajdu-Cheney syndrome - new data and literature review
}

\author{
James F. H. Pittaway ${ }^{1 *}$, Christopher Harrison ${ }^{2}$, Yumie Rhee ${ }^{3}$, Muriel Holder-Espinasse ${ }^{4}$, Alan E. Fryer ${ }^{5}$, Tim Cundy ${ }^{6}$, \\ William M. Drake ${ }^{1}$ and Melita D. Irving ${ }^{4}$
}

\begin{abstract}
Background: Hajdu-Cheney syndrome (HCS) (\#OMIM 102500) is a rare, autosomal dominant condition that presents in early childhood. It is caused by mutations in the terminal exon of NOTCH2, which encodes the transmembrane $\mathrm{NOTCH} 2$ receptor. This pathway is involved in the coupled processes of bone formation and resorption. The skeletal features of HCS include acro-osteolysis of the digits and osteoporosis commonly affecting vertebrae and long bones. Fractures are a prominent feature and are associated with significant morbidity. There is no specific treatment, but with both acro-osteolysis and generalized osteoporosis, it is possible that anti-resorptive treatment might be of benefit. However, to date only a few case reports have evaluated the effectiveness of bisphosphonate treatment.
\end{abstract}

Methods: We describe the clinical features, treatment regimens and response to bisphosphonate treatment in 7 newly described patients aged 6-39 with HCS, and pooled the data with that from 8 previously published cases (a total of 17 courses of treatment in 15 individuals).

Results: The mean lumbar spine bone mineral density (BMD) z-score before treatment was - 2.9 (SD 1.2). In 14 courses of treatment (82\%), there was an increase in BMD with bisphosphonate treatment, but the impact (in terms of change in spinal BMD $z$-score) appeared to be less with advancing age $(p=0.01)$. There was no evidence that acro-osteolysis was prevented.

Conclusions: Although individual response is variable and age-related, the data support a role for bisphosphonates in preventing or treating spinal osteoporosis in HCS, but bone loss from the lumbar spine may be rapid after cessation.

Keywords: Bisphosphonates, Diseases, Genetic disorders, Human studies, Dual energy x-ray absorptiometry (DEXA)

\section{Background}

Hajdu-Cheney syndrome (HCS) (\#OMIM 102500) is a rare, autosomal dominant condition associated with a distinctive skeletal phenotype that includes both generalized osteoporosis and localized acro-osteolysis [1, 2]. It presents in early childhood with characteristic dysmorphic facial features and variable congenital abnormalities, such as polycystic kidneys and heart disease [3-5]. Vertebral and long bone fractures, a consequence of the osteoporosis, are common. Other skeletal findings include premature tooth loss, fibular deformities, scoliosis, joint

\footnotetext{
* Correspondence: jfhpittaway@doctors.org.uk

${ }^{1}$ Department of Endocrinology, St Bartholomew's Hospital, West Smithfield, London EC1A 7BE, UK

Full list of author information is available at the end of the article
}

hyperlaxity, platybasia and basilar invagination [6]. HCS is caused by mutations in the terminal exon of $\mathrm{NOTCH} 2$, which encodes the transmembrane $\mathrm{NOTCH} 2$ receptor [7]. Despite its dominant inheritance many cases do not have a family history as the new mutation rate is high (55\%). Signaling through the NOTCH pathway is responsible for cell differentiation and, specifically in the precisely coupled processes of bone formation and bone resorption [8]. In vitro studies suggest the $\mathrm{NOTCH}$ pathway plays a role in committing mesenchymal stem cells to the osteoblast lineage, thereby stimulating osteoclastogenesis [9].

Recurrent vertebral and non-vertebral fracture is a major cause of morbidity in patients with HCS and the neurological consequences of progressive platybasia are 
a significant contributor to the premature mortality associated with the condition. Biochemical and histomorphometric evidence suggests that a high bone turnover state underlies the acro-osteolysis and spinal osteoporosis [10,11]. A recent histomorphometric study has emphasized marked cortical osteopenia underlying the liability to fracture [12].

A number of clinicians have trialed bisphosphonate therapy in an attempt to retard acro-osteolysis and vertebral bone loss. Only a few case reports of bisphosphonate treatment in HCS have been published [5, 12-14] and with such a rare syndrome, the potential exists for individual anecdote unduly to affect clinical decisionmaking.

Here, we describe the outcome of bisphosphonate treatment in seven additional patients with HCS, pooled from different centers worldwide. Incorporating data from the previously published case reports, we have attempted to provide useful information on the effectiveness of bisphosphonate treatment on acro-osteolysis and osteoporosis in HCS.

\section{Methods}

Seven patients ( 5 female; median age 13 years, range 639) were studied retrospectively. All carried a diagnosis of HCS based on typical clinical and radiographic features, and five had genetic confirmation. Three of the seven were included in a report that described the presence of NOTCH2 mutations in the syndrome [7]. The clinical indications leading to the decision to trial bisphosphonate were recurrent fracture and/or declining bone mineral density (BMD), measured by dual-energy X-ray absorptiometry (DXA). A variety of regimens were used but bisphosphonate therapy was given for a minimum of $1 \frac{1}{2}$ years. The treatment regimens for individual patients are given in Table 1 . One subject (Case 2) was studied for two separate periods. She had treatment with intravenous pamidronate aged 8 to 10 , then had sequential BMD scans but no treatment until age 24 when she was treated with intravenous zoledronate. We have also reviewed data from eight other cases that have been described in recent papers $[5,12-15]$.

Progression of acro-osteolysis was assessed from serial radiographs of the hands and feet. BMD at the lumbar spine was measured by dual-energy $x$-ray absorptiometry. In each case the same machine was used for initial and follow-up scans.

The densitometers used to measure BMD were as follows: GE Lunar Prodigy Advance (Lunar, Madison, WI, USA; cases 1 and 4), Lunar DPX-L (Lunar, Madison, WI, USA; cases 2 (aged 8) and 7), Hologic QDR-4500A (Hologic, Waltham, MA, USA; case 3), GE Lunar Prodigy (Lunar, Madison, WI, USA; cases 2 (aged 24) and 5), Hologic 2000 (Hologic, Waltham, MA, USA; case 6).
Because different densitometers were used and the wide age range we report the BMD results as age-related $\mathrm{SD}$ scores (z-scores), compared to the manufacturers' normal ranges. Mean values were compared by paired $t$ test and correlations by the Pearson method using IBM SPSS Statistics (version 24.0 for Windows).

\section{Results}

Table 1 summarizes the clinical data, including the age at starting treatment, the regimen given and its duration. Six of the seven subjects had suffered fractures. The mean $\mathrm{z}$-score, measured after a median $4 \frac{1}{2}$ years' bisphosphonate treatment, had increased from - 3.4 (SD 1. 2) to -2.7 (1.4), but this difference was not statistically significant $(p=0.158)$. The response however appeared greater in the young. This was illustrated in subject 2, whose spinal BMD z-score increased by 1.4 SD when treated with pamidronate from 8 to 10 years of age, but when treated with zoledronate at age 24 had only a 0.4 $\mathrm{SD}$ increase over a comparable time. In the interval between the two treatment periods, despite enjoying reasonable health and reaching a normal height, her BMD z-score declined markedly with a loss of $2.6 \mathrm{SD}$ over 14 years (Fig. 1).

Table 2 (cases 8-15) lists data extracted from eight other published reports [5, 12-15]. One subject (case 9 [12],) had two separate periods of bisphosphonate treatment evaluated. Including these in the analysis, there was a strong inverse relationship between change in spine BMD z-score and the age at which treatment was started (Pearson correlation coefficient $-0.624, p=0.01$; Fig. 2). The only person $>15$ years old whose z-score increased by $>0.6$ was a 57 year-old woman (case 15 [13],), in whom accelerated bone loss post-menopause may have been a factor.

Changes in acro-osteolysis in the hands were inconsistently reported. In 17 treatment periods (in 15 people) no data was reported in six; in 7 cases there was no response, in three cases progression was documented and in only one case was progression said to have 'slowed'. There were no documented cases of improvement. Figure 3 illustrates the progressive radiographic change over a twelve-year period in subject 7, who had the most prolonged course of bisphosphonate treatment. Loss of dental bone and teeth was not systematically assessed in any of the cases.

\section{Discussion}

HCS is a rare genetic condition, characterized by generalized osteoporosis and focal bone loss (acro-osteolysis and dental) $[1,2]$. In the combined group we describe $75 \%$ of the patients over the age of 10 had vertebral fractures. A number of previously published cases have suggested that the generalized osteoporosis, as assessed by 


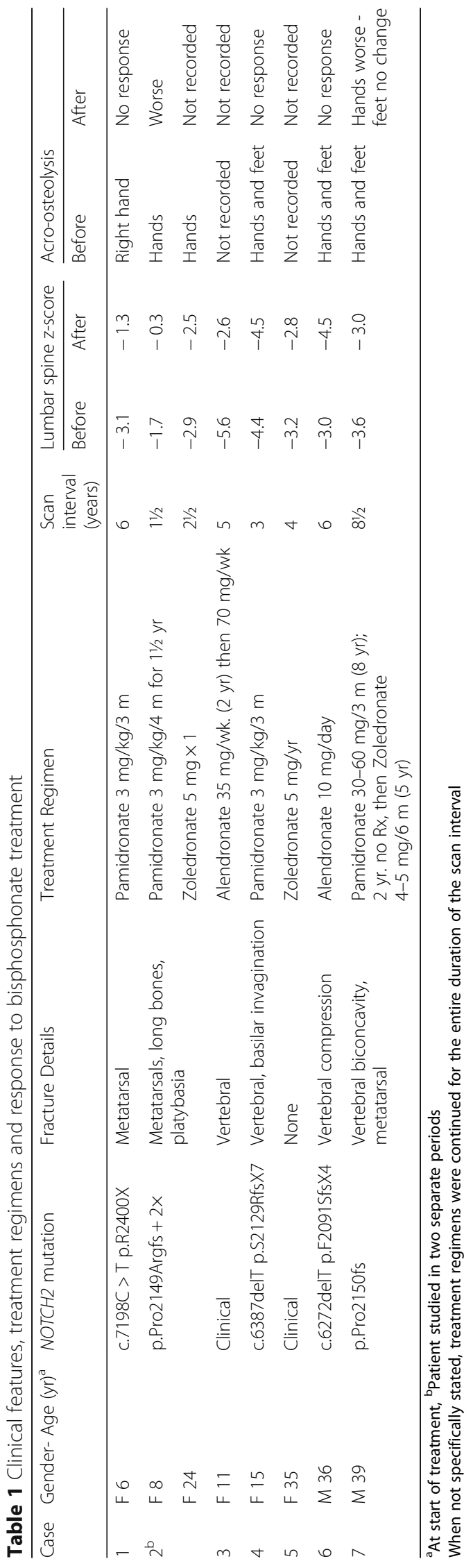




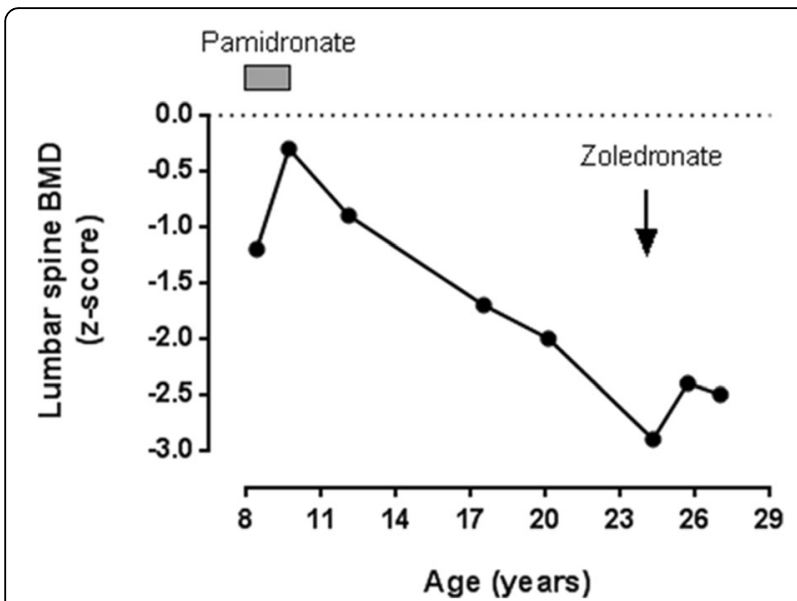

Fig. 1 Sequential changes in lumbar spine $z$-score in one subject (case 2), treated with pamidronate from 8 to 10 years of age, and zoledronate at age 24 . The increment in $z$-score was lower when she was treated as an adult. Between these two treatment periods her BMD $z$-score fell by $2.6 \mathrm{SD}$ over 14 years

lumbar spine $\mathrm{BMD}$, is to some degree responsive to treatment using bisphosphonates $[12,15]$. In the expanded data set of 17 courses of treatment in 15 people, there was some improvement in lumbar BMD in 14 $(82 \%)$, but the responses were variable. Some of this variability might be attributable to the use of regimens of varying intensity and duration, but the age at the start of treatment also seems to be important, with greater responses in the youngest patients.

It is to be expected that the growing skeleton will respond best to bisphosphonates, which work in the growing skeleton both by reducing resorption of the secondary spongiosa, so increasing trabecular bone mass, and by inhibiting endosteal bone resorption during the modelling of long bones, so increasing cortical thickness [16]. It is noticeable from Fig. 2 that the response of BMD to bisphosphonates in HCS becomes muted after the age of 15 - well before the age that peak skeletal mass is reached. Most forms of juvenile osteoporosis arise from the failure of bone acquisition rather than accelerated bone loss, but two of the cases illustrate that bone loss after cessation of bisphosphonates can be very rapid in HCS. As shown in Fig. 2, the teenage years and early twenties of case 2 were marked by a substantial loss of BMD (2.6 SD in 14 years), and case 10 (Table 2), reported by Sakka et al. [12], lost 2.2 SD between the ages of 14 and 19. It is not clear if this bone loss could have been prevented with continued bisphosphonate treatment, and clearly this is an important question for future research. There is insufficient data to comment on fracture rate or whether bisphosphonates might prevent platybasia or the loss of dental bone that underlies the characteristic premature tooth loss in HCS.

We found no evidence that bisphosphonate therapy could promote healing of acro-osteolysis, and indeed progression was documented in some subjects. This suggests either a different mechanism underlies the focal bone loss, that is not amenable to osteoclast inhibition, or that there is inadequate bioavailability of bisphosphonate. The data are insufficient to know whether the rate of progression would have been faster without bisphosphonate treatment.

Table 2 Clinical features, treatment regimens and response to bisphosphonate treatment - previously published cases

\begin{tabular}{|c|c|c|c|c|c|c|c|c|c|}
\hline \multirow[t]{2}{*}{ Case [Ref] } & \multirow[t]{2}{*}{ Gender - Age $(y r)^{a}$} & \multirow{2}{*}{$\begin{array}{l}\text { NOTCH2 } \\
\text { mutation }\end{array}$} & \multirow[t]{2}{*}{ Fracture Details } & \multirow[t]{2}{*}{ Treatment Regimen } & \multirow{2}{*}{$\begin{array}{l}\text { Scan interval } \\
\text { (years) }\end{array}$} & \multicolumn{2}{|c|}{ Lumbar spine z-score } & \multicolumn{2}{|c|}{ Acro-osteolysis } \\
\hline & & & & & & Before & After & Before & After \\
\hline 8. [5] & M 2 & $\begin{array}{l}\text { c.6909dup } \\
\text { p.12304HfsX9 }\end{array}$ & Metatarsals & $\begin{array}{l}\text { Pamidronate } \\
3 \mathrm{mg} / \mathrm{kg} / 3 \mathrm{~m}\end{array}$ & 5 & -4.1 & -0.7 & $\begin{array}{l}\text { Hands and } \\
\text { feet }\end{array}$ & No response \\
\hline \multirow[t]{2}{*}{ 9. ${ }^{b}[12]$} & M. $61 / 2$ & p.Val2221Glufs* & Long bones & $\begin{array}{l}\text { Pamidronate } \\
1 \mathrm{mg} / \mathrm{kg} / 3 \\
\mathrm{~m}-1 \mathrm{yr} \\
\text { Alendronate } \\
35-70 \mathrm{mg}-51 / 2 \mathrm{yr}\end{array}$ & 6 & -1.9 & +0.1 & $\begin{array}{l}\text { Hands and } \\
\text { feet }\end{array}$ & No response \\
\hline & M. $171 / 2$ & & & $\begin{array}{l}\text { Zoledronate } \\
5 \mathrm{mg} \times 1 \text { age } 171 / 2\end{array}$ & $21 / 2$ & -2.1 & -1.7 & $\begin{array}{l}\text { Hands and } \\
\text { feet }\end{array}$ & Not recorded \\
\hline 10 [15]. & F.10 & Clinical & $\begin{array}{l}\text { Vertebral, metatarsal, } \\
\text { metacarpal }\end{array}$ & $\begin{array}{l}\text { Pamidronate } \\
4 \mathrm{mg} / \mathrm{kg} / 3 \mathrm{~m}\end{array}$ & 2 & -3.4 & -0.7 & $\begin{array}{l}\text { Hands and } \\
\text { feet }\end{array}$ & Not recorded \\
\hline $11[12]$ & M.101/2 & Clinical & Vertebral, long bones & $\begin{array}{l}\text { Alendronate } \\
35-70 \mathrm{mg} / \mathrm{wk}\end{array}$ & 4 & -0.5 & +2.8 & $\begin{array}{l}\text { Hands and } \\
\text { feet }\end{array}$ & $\begin{array}{l}\text { Slowed } \\
\text { progression }\end{array}$ \\
\hline 12 [12]. & F.15 & p.Leu2301* & Vertebral, long bones & $\begin{array}{l}\text { Zoledronate } \\
50 \mu \mathrm{g} / \mathrm{kg} / 6 \mathrm{~m}\end{array}$ & 3 & -3.4 & -2.4 & $\begin{array}{l}\text { Hands and } \\
\text { feet }\end{array}$ & No response \\
\hline 13 [12]. & M.151/2 & $p G \ln 2263^{*}$ & Vertebral & $\begin{array}{l}\text { Zoledronate } \\
50 \mu \mathrm{g} / \mathrm{kg} / 6 \mathrm{~m}\end{array}$ & $11 / 2$ & -0.8 & -0.7 & $\begin{array}{l}\text { Hands and } \\
\text { feet }\end{array}$ & Not recorded \\
\hline 14 [14]. & F 41 & $\begin{array}{l}\text { c.6854delA } \\
\text { p.Q2285RfsX9 }\end{array}$ & None & $\begin{array}{l}\text { Zoledronate } \\
5 \mathrm{mg} / \mathrm{yr}\end{array}$ & 3 & -2.5 & -2.6 & Hands & Worse \\
\hline 15 [13]. & F 57 & Clinical & Vertebral compression & $\begin{array}{l}\text { Alendronate } \\
10 \mathrm{mg} / \text { day }\end{array}$ & 4 & -3.6 & -2.7 & Hands & No response \\
\hline
\end{tabular}

${ }^{\mathrm{a}}$ At start of treatment, ${ }^{\mathrm{b}}$ Patient studied in two separate periods 


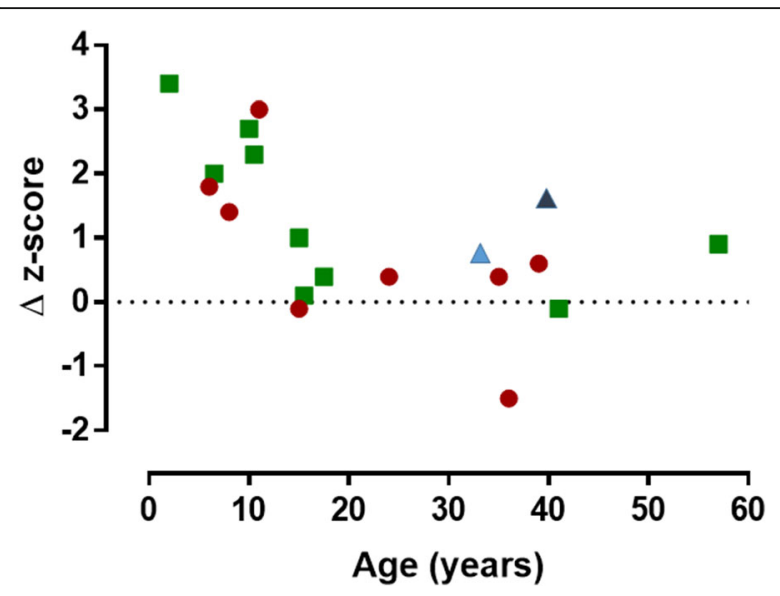

Fig. 2 Scatterplot showing the negative correlation between change $(\Delta)$ in lumbar spine BMD z-score with bisphosphonate treatment in relation to the age at which treatment was started (17 courses of treatment in 15 individuals). Pearson correlation coefficient -0.624 $(p=0.01)$. The new cases (from Table 1 ) are shown by green circles and the cases previously described in the literature (Table 2) are shown by red squares. The light blue triangle indicates the response in the patient described by Adami et al. [17] who was treated with denosumab for 2 years; the dark blue triangle the patient described by McKiernan [18] who was treated with both pamidronate and teriparatide for two years

Adami et al. reported the effects of treatment with another inhibitor of bone resorption, the RANKL-inhibitor denosumab, in a 33 year-old woman with HCS who had previously been treated with bisphosphonates and strontium [17]. The change in lumbar spine BMD (+0.5 SD over 2 years) was much in line with the results presented in this paper and acro-osteolysis progressed. McKiernan described the effects of combination therapy with an anabolic agent as well as an anti-resorptive agent in a 39 year-old woman with HCS treated for 2 years with both teriparatide and pamidronate. Her lumbar spine BMD z-score improved from -7.1 to -5.5 , but over the same period steroid treatment (prescribed for a different indication) was withdrawn. There was no change in acro-osteolysis [14]. For comparison, data from these two cases has been included in Fig. 2.

Given that the molecular basis of HCS is now known [7], and that bisphosphonate therapy in is essentially empirical, opportunities to explore treatment strategies around signaling through NOTCH2 should be considered. In HCS, mutations in the terminal exon of NOTCH2 lead to the creation of a stop codon upstream of the PEST (proline (P), glutamic acid (E), serine (S), and $(\mathrm{T})$ threonine) domain, responsible for ubiquitination and degradation of $\mathrm{NOTCH}$, leading to a persistence of NOTCH2 signaling $[7,16]$. In murine models, this has been shown to increase bone resorption due to a direct effect on osteoclast precursors and due to an increase in RANKL by the osteoblast increasing osteoclastogenesis [17].

$\mathrm{NOTCH}$-ligand interactions result in release of the $\mathrm{NOTCH}$ intracellular domain (NICD) which translocates to the nucleus and forms a protein complex with recombination signal-binding protein for immunoglobulin $\mathrm{kJ}$ region (Rbpjk) and Mastermind-like to induce transcription of downstream effectors of this signaling pathway (transcription factors of the hairy enhancer of split (HES) gene family, HES and HEY) [18]. Interruption of this pathway promises a more targeted approach to

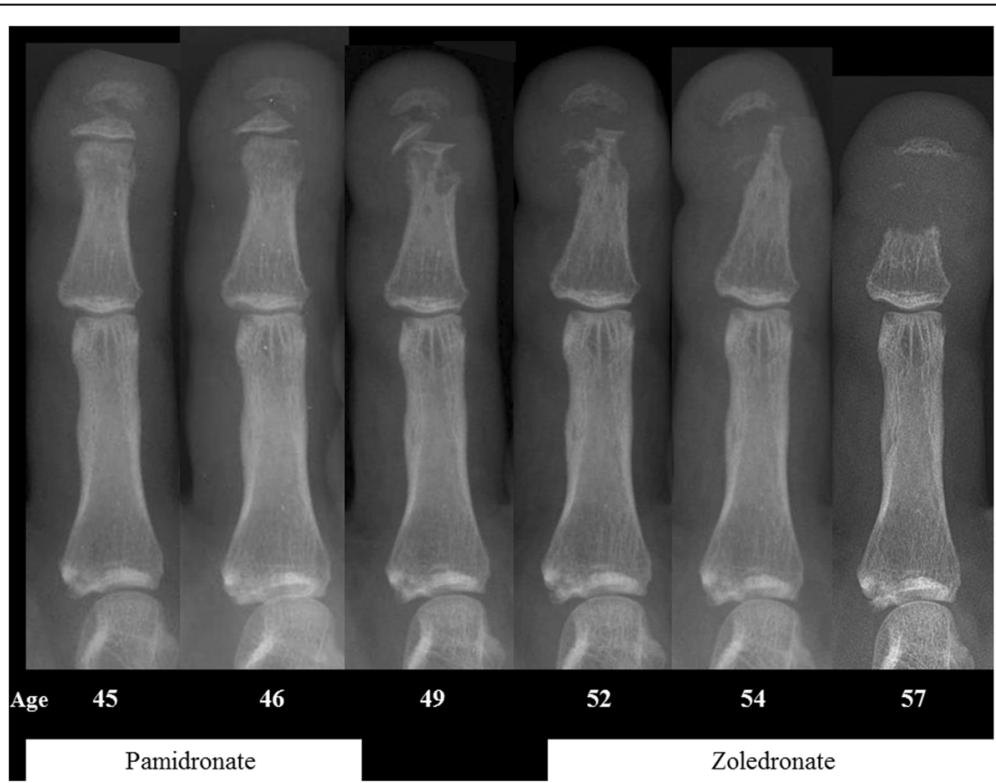

Fig. 3 Progression of acro-osteolysis despite treatment with bisphosphonates. Radiographs of the right index finger of subject 7, taken over 12 years. The timing of bisphosphonate treatment is indicated 
treatment. Possible drug targets in the pathway include inhibitors of the enzyme complexes that cleave the $\mathrm{NOTCH}$ extra- and intracellular domains (alpha and gamma secretase, respectively) or antibodies to the $\mathrm{NOTCH} 2$ receptor itself. An antibody to NOTCH2 has been shown to reverse the osteopenic phenotype in HCS mutant mice [19]. NOTCH signaling dysfunction is also implicated in the pathogenesis of a number of hematological and solid tumor malignancies. Gamma secretase inhibitors are in clinical trials in such malignancies, and although not specific to $\mathrm{NOTCH} 2$, these results could potentially inform novel therapeutic approaches in HCS [20].

\section{Conclusions}

We have described the responses of acro-osteolysis and spinal BMD to treatment with bisphosphonates in a new cohort of patients with Hajdu-Cheney syndrome, and reviewed the previously published literature. Our data suggest that bisphosphonate treatment does not arrest acro-osteolysis, but spinal BMD is improved. The greatest effect is seen in younger patients and bone loss can be rapid when bisphosphonates are discontinued. Although this is the largest group described to date, the numbers are still small, as is typical with such rare diseases, and larger numbers are required to confirm the efficacy of bisphosphonate treatment. Better therapeutic options may be available in the future with increased understanding of the molecular pathogenesis of the condition and the growing experience of gamma secretase inhibitors in clinical oncology.

\section{Acknowledgements}

We would like to thank Professor lan Reid, University of Auckland, for permission to report data from a patient under his care.

\section{Funding}

Not applicable.

\section{Availability of data and materials}

The datasets used and/or analysed during the current study are available from the corresponding author on reasonable request.

\section{Congresses}

Presented in part at the International Skeletal Dysplasia Society meeting in Brugge, Belgium 2017

\begin{abstract}
Authors' contributions
Authors' roles: Data provision: $\mathrm{CH}, \mathrm{TC}, \mathrm{MH}, \mathrm{OK}, \mathrm{AF}, \mathrm{WD}, \mathrm{MI}$. Data collection, analysis and interpretation: JP, TC, MI and WD. Drafting manuscript: JP, MI, TC and WD. Revising manuscript content: JP, TC, MI and WD. Approving final version of manuscript: JP, CH, TC, MH, OK, AF, Ml and WD. JP takes responsibility for the integrity of the data analysis. All authors read and approved the final manuscript.
\end{abstract}

\section{Ethics approval and consent to participate}

All procedures performed in studies involving human participants were in accordance with the ethical standards of the institutional and/or national research committee and with the 1964 Helsinki declaration and its later amendments or comparable ethical standards. For this type of study formal consent is not required.
Consent for publication

Not applicable

\section{Competing interests}

Dr. Rhee reports personal fees from Amgen, personal fees from Eli Lilly, outside the submitted work. All other authors declare that they have no competing interests.

\section{Publisher's Note}

Springer Nature remains neutral with regard to jurisdictional claims in published maps and institutional affiliations.

\section{Author details}

'Department of Endocrinology, St Bartholomew's Hospital, West Smithfield, London EC1A 7BE, UK. ${ }^{2}$ Department of Clinical Genetics, Alder Hey Children's NHS Foundation Trust, E Prescot Rd, Liverpool L14 5AB, UK. ${ }^{3}$ Department of Internal Medicine, Severance Hospital, Endocrine Research Institute, Yonsei University College of Medicine, 50-1 Yonsei-ro, Seodaemun-gu, Seoul, Republic of Korea. ${ }^{4}$ Department of Clinical Genetics, Guy's and St Thomas' NHS Foundation Trust, Great Maze Pond, London SE1 9RT, UK. ${ }^{5}$ Department of Clinical Genetics, Liverpool Women's NHS Foundation Trust, Crown Street, Liverpool L8 7SS, UK. ${ }^{6}$ Department of Medicine, University of Auckland, 85 Park Rd, Grafton, Auckland 1023, New Zealand.

Received: 24 January 2018 Accepted: 27 March 2018

Published online: 04 April 2018

\section{References}

1. Hajdu N, Kauntze R. Cranio-skeletal dysplasia. Br J Radiol. 1948;21(241):42-8. https://doi.org/10.1259/0007-1285-21-241-42.

2. Cheney WD. Acro-Osteolysis. Am J Roentgenol Radium Therapy Nucl Med. 1965:94:595-607.

3. Albano LM, Bertola DR, Barba MF, Valente M, Robertson SP, Kim CA. Phenotypic overlap in Melnick-needles, serpentine fibula-polycystic kidney and Hajdu-Cheney syndromes: a clinical and molecular study in three patients. Clin Dysmorphol. 2007;16(1):27-33. https://doi.org/10.1097/01.mcd. 0000228418.74413 .52$.

4. Brennan AM, Pauli RM. Hajdu-Cheney syndrome: evolution of phenotype and clinical problems. Am J Med Genet. 2001;100(4):292-310.

5. Battelino N, Writzl K, Bratanic N, Irving MD, Novljan G. End-stage renal disease in an infant with Hajdu-Cheney syndrome. Ther Apher Dial. 2016; 20(3):318-21. https://doi.org/10.1111/1744-9987.12444.

6. Canalis E, Zanotti S. Hajdu-Cheney syndrome: a review. Orphanet J Rare Dis. 2014;9:200. https://doi.org/10.1186/s13023-014-0200-y.

7. Simpson MA, Irving MD, Asilmaz E, Gray MJ, Dafou D, Elmslie FV, Mansour S, Holder SE, Brain CE, Burton BK, Kim KH, Pauli RM, Aftimos S, Stewart H, Kim CA, Holder-Espinasse M, Robertson SP, Drake WM, Trembath RC. Mutations in NOTCH2 cause Hajdu-Cheney syndrome, a disorder of severe and progressive bone loss. Nat Genet. 2011;43(4):303-5. https://doi.org/10.1038/ng.779.

8. Hilton MJ, Tu X, Wu X, Bai S, Zhao H, Kobayashi T, Kronenberg HM, Teitelbaum SL, Ross FP, Kopan R, Long F. Notch signaling maintains bone marrow mesenchymal progenitors by suppressing osteoblast differentiation. Nat Med. 2008;14(3):306-14. https://doi.org/10.1038/nm1716.

9. Fukushima H, Nakao A, Okamoto F, Shin M, Kajiya H, Sakano S, Bigas A, Jimi E, Okabe K. The association of Notch2 and NF-kappaB accelerates RANKLinduced osteoclastogenesis. Mol Cell Biol. 2008;28(20):6402-12. https://doi. org/10.1128/MCB.00299-08.

10. Brown DM, Bradford DS, Gorlin RJ, Desnick RJ, Langer LO, Jowsey J, Sauk JJ. The acro-osteolysis syndrome: morphologic and biochemical studies. J Pediatr. 1976;88(4 Pt 1):573-80.

11. Udell J, Schumacher HR Jr, Kaplan F, Fallon MD. Idiopathic familial acroosteolysis: histomorphometric study of bone and literature review of the Hajdu-Cheney syndrome. Arthritis Rheum. 1986;29(8):1032-8.

12. Drake WM, Hiorns MP, Kendler DL. Hadju-Cheney syndrome: response to therapy with bisphosphonates in two patients. J Bone Miner Res. 2003;18(1): 131-3. https://doi.org/10.1359/jbmr.2003.18.1.131.

13. Hwang S, Shin DY, Moon SH, Lee EJ, Lim SK, Kim OH, Rhee Y. Effect of Zoledronic acid on Acro-Osteolysis and osteoporosis in a patient with Hajdu-Cheney syndrome. Yonsei Med J. 2011:52(3):543-6. https://doi.org/10. 3349/ymj.2011.52.3.543. 
14. McKiernan FE. Integrated anti-remodeling and anabolic therapy for the osteoporosis of Hajdu-Cheney syndrome: 2-year follow-up. Osteoporosis Int 2008;19(3):379-80. https://doi.org/10.1007/s00198-007-0461-6.

15. Galli-Tsinopoulou A, Kyrgios I, Giza S, Giannopoulou EZ, Maggana I, Laliotis N. Two-year cyclic infusion of pamidronate improves bone mass density and eliminates risk of fractures in a girl with osteoporosis due to HajduCheney syndrome. Minerva Endocrinol. 2012;37(3):283-9.

16. Isidor B, Lindenbaum P, Pichon $O$, Bezieau S, Dina C, Jacquemont S, MartinCoignard D, Thauvin-Robinet C, Le Merrer M, Mandel JL, David A, Faivre L, Cormier-Daire V, Redon R, Le Caignec C. Truncating mutations in the last exon of NOTCH2 cause a rare skeletal disorder with osteoporosis. Nat Genet. 2011;43(4):306-8. https://doi.org/10.1038/ng.778.

17. Canalis E, Schilling L, Yee SP, Lee SK, Zanotti S. Hajdu Cheney mouse mutants exhibit osteopenia, increased Osteoclastogenesis, and bone resorption. J Biol Chem. 2016;291(4):1538-51. https://doi.org/10.1074/jbc M115.685453.

18. Iso T, Kedes L, Hamamori Y. HES and HERP families: multiple effectors of the Notch signaling pathway. J Cell Physiol. 2003;194(3):237-55. https://doi.org/ 10.1002/jcp.10208.

19. Canalis E, Sanjay A, Yu J, Zanotti S. An antibody to Notch2 reverses the Osteopenic phenotype of Hajdu-Cheney mutant male mice. Endocrinology. 2017:158(4):730-42. https://doi.org/10.1210/en.2016-1787.

20. Olsauskas-Kuprys R, Zlobin A, Osipo C. Gamma secretase inhibitors of Notch signaling. Oncotargets Ther. 2013;6:943-55. https://doi.org/10.2147/Ott. S33766.

\section{Submit your next manuscript to BioMed Central and we will help you at every step:}

- We accept pre-submission inquiries

- Our selector tool helps you to find the most relevant journal

- We provide round the clock customer support

- Convenient online submission

- Thorough peer review

- Inclusion in PubMed and all major indexing services

- Maximum visibility for your research

Submit your manuscript at www.biomedcentral.com/submit 